\title{
Discursos que (con)formam corpos grávidos: da medicina à educação física*
}

\author{
Maria Simone Vione Schwengber** \\ Dagmar Estermann Meyer ${ }^{* * *}$
}

\begin{abstract}
Resumo
Este artigo é parte de uma pesquisa inspirada nos estudos de gênero que se aproximam das teorizações de Michel Foucault (1988). Nele discutimos um processo educativo contemporâneo que denominamos de "politização do feminino $e$ da maternidade", um processo que, por extensão, inclui a "politização do corpo grávido". Para fazer essa discussão, examinamos a revista Pais \& Filhos, de 1968 a 2004, utilizandonos das estratégias metodológicas da análise de discurso. Das análises que resultaram dessa investigação, focalizamos aqui um movimento que permite visualizar uma rede mais ampla de cuidados e de novos saberes que, ao definir o que chama de "bom" pré-natal, também produz diferentes posições de sujeito, dentre elas, a da boa mãe, aquela que cuida e se cuida.
\end{abstract}

Palavras-chave: Educação do corpo, Gênero, Maternidade, Mídia.

* Recebido para publicação em fevereiro de 2009, aceito em outubro de 2010.

** Doutora em Educação pela Universidade Federal do Rio Grande do Sul. Professora do Mestrado em Educação, do Programa de Pós-Graduação da Universidade Regional do Noroeste do Estado do Rio Grande do Sul (UNIJUI). UNIJUÍ.simone@unijui.edu.br

**** Doutora em Educação. Professora na Faculdade de Educação da Universidade Federal do Rio Grande do Sul. Pesquisadora com bolsa PQ do CNPq e pesquisadora do GEERGE-UFRGS. dagmaremeyer@yahoo.com.br

cadernos pagu (36), janeiro-junho de 2011:283-314. 
Discursos que (con)formam corpos grávidos

Discourses that (Con)Form Pregnant Bodies:

from Medicine to Physical Education

\begin{abstract}
The present article is an integral part of a research inspired in the fields of Gender Studies that approximate theorizations by Michel Foucault (1998; 1997). We discuss the contemporary educative process as "politicization of femininity and motherhood", a process that, in its extension, includes the "politicization of the pregnant body". In order to conduct this discussion, we have examined issues of Pais \& Filhos, a magazine published from 1968 to 2004, using methodological strategies of analysis of discourse. From the analyses resulting from that investigation, we have spotted a movement that allows for the visualization of a wider network of care and new knowledge, defined as "good" prenatal care, that produces different subject positions; one of these positions is that of a good mother, i.e. that one who looks after herself and others.
\end{abstract}

Key Words: Body Education, Gender, Motherhood, Media. 
Maria Simone Schwengber e Dagmar Meyer

\section{A mais antiga das artes: ter filhos $e$ tornar-se mãe ${ }^{1}$}

Ser mãe envolve, contemporaneamente, uma discursividade cada vez mais complexa que é amplamente produzida e divulgada em diversos artefatos da cultura, como poemas, canções, romances literários, filmes, novelas, documentários e também diferentes ciências, mídias e propagandas. Por estarem inseridas nesses discursos e deles serem sujeitos, muitas mulheres começam a ter acesso às aprendizagens muito tempo antes de pensarem na possibilidade de virem a tornar-se mães.

$\mathrm{Na}$ cultura ocidental, ser mãe remete, ao mesmo tempo, para uma etapa e um estado específico da vida feminina que envolve a gestação, o parto e a lactação e também para cuidados anteriores e posteriores ao parto; estes últimos constituem um conjunto de ações de longo prazo, dentre as quais se destaca a maternagem, que envolve também criar e educar as crianças geradas. Um recuo no tempo, no entanto, permite-nos dizer que ser mãe foi significado, valorizado e propagado de formas muito diversas nessa cultura. Badinter (1985), por exemplo, assinala que há três séculos, a função maternal não era objeto de atenção nem de valorização por parte da sociedade, que as mulheres não eram glorificadas pelo fato de serem mães e que o amor maternal não era um valor social nem moral. Ela argumenta (1985:185) que essa situação se altera apenas em finais do século XVIII, quando "se opera uma espécie de revolução das mentalidades" e surgem, pela primeira vez, recomendações escritas para que "as mães se ocupem pessoalmente dos seus filhos".

Para Foucault (1997), não é forçado argumentar que, nas sociedades modernas ocidentais, a família foi a primeira instância de articulação de investimentos do que se foi definindo como políticas relativas à boa saúde. Dentro da família, pela sua

1 Ver a Tese de Doutorado em Educação de Schwengber, 2006, e outro trabalho, de Schwengbe e Meyer, 2007, publicado como desdobramento da tese. 
Discursos que (con)formam corpos grávidos

capacidade de gestar e parir, foram os corpos das mulheres os primeiros investidos de uma função política - nesse contexto, produzir bons e saudáveis cidadãos (Costa, 1979). A educação de corpos reprodutivos apresentou-se também nas sociedades antigas, mas é "somente a partir do século XIX que a população e a reprodução constituíram-se em objetos a serem regulados" pelos Estados modernos, segundo Foucault (1988:28). De acordo com o autor, acreditava-se que o controle das sociedades modernas não deveria ser exercido simplesmente por meio da consciência e da razão, pois "foi no biológico, no somático, no corporal que, antes de tudo, investiu a sociedade moderna" (Foucault, 1988:28). Ainda segundo Foucault, foi a primeira vez que a sociedade, de forma sistemática, tratou dos corpos - destacamos aqui os das mulheres - como algo que se deveria "gerir, inserir em sistemas de utilidades, regular para o bem de todos, fazer funcionar segundo padrão ótimo" (Foucault, 1988:27).

No contexto brasileiro, isso que chamamos de politização da maternidade foi se construindo $e$, gradualmente, atingindo diferentes âmbitos e planos da vida social (Meyer, 2006). Cientificamente legitimados, os médicos, aqui, iniciaram o processo de maternalização, contando com o apoio do Estado. Para o aparato médico sanitário ${ }^{2}$, as mulheres mães eram consideradas como frágeis, quando não inferiores, "ignorantes $e$ negligentes" (Luz, 2003:18), e, por isso, elas precisavam de conselhos dos profissionais da saúde, sobretudo no que se referia às formas de viver $e$ pensar o processo de condução $e$ implementação da reprodução biológica e social. Portanto, essas diretrizes estavam associadas ao papel social iluminista de educação, em que a maternidade, ao mesmo tempo em que era apresentada como sendo "o" destino natural da mulher, também comportava um paradoxo - as mulheres deveriam aprender, precisavam ser educadas como mães (Badinter, 1985).

2 Os médicos propunham-se a ser os grandes reformuladores sociais pela posição legitimada de seus saberes científicos (Luz, 1982:18). 
Essas diretrizes circulavam e configuravam-se por meio das políticas higienistas do Estado brasileiro que se voltaram para o controle dos corpos das mulheres, conjugando-se com a nova geração de ginecologistas, obstetras, puericultores e médicos sociais, que foram, pouco a pouco, modificando grande parte das experiências e vivências da maternidade: o parto em hospital público; o acompanhamento da gravidez; os conselhos acerca de como criar os/as filhos/as; as ideias sobre a reprodução e, mais especificamente, a puericultura intra-útero (Martins, 2004).

Ao redor das mulheres afirmava-se, cada vez mais, um conjunto de práticas e políticas voltadas para a gestão e o aperfeiçoamento de seus corpos, mesmo antes da concepção. $\mathrm{O}$ discurso médico sanitarista visava a convencê-las acerca de sua responsabilidade social com o processo da gravidez e com a maternagem, uma vez que, "se é a fisiologia da mulher que lhe permite carregar, é ela, portanto, que pode melhor maternar" (Santos, 1998:145). Nesses discursos, crianças saudáveis seriam o prenúncio certeiro de homens/mulheres fortes, e o alcance dessa meta dependia dos processos educativos que envolviam os corpos das mães; cuidar bem das crianças começa pelos cuidados adequados com os corpos das mulheres gestantes. Percebe-se, assim, a vitalidade e a continuidade de uma ideia moderna que perdura até os nossos dias: a de que a saúde dos/as filhos/as é o espelho da saúde da mãe.

Como observa Scavone (2001), é a partir da modernidade que começam a circular as primeiras ideias de uma puericultura intraútero, a qual pressupõe que:

(...) a criança, no útero, é quase sempre a base da saúde do infante por nascer; a criança bem conformada, sã, robusta $e$ inteligente depende dos cuidados intra-uterinos. (...) 0 descanso da mãe, a sua nutrição, o ambiente higiênico exercem uma influência sobre o produto da concepção (a criança) (Scavone, 2001:55). 
Discursos que (con)formam corpos grávidos

Esses pressupostos introduziram inovações, tais como a de que a preparação para a gestação de um/a filho/a começa antes da concepção e, como decorrência disso, se deveriam educar as mulheres para cuidarem de seus corpos muito antes de elas se decidirem a ter filhos/as. Coloca-se em movimento uma série de inovações pedagógicas cujo alvo de investimento passa ser o corpo da gestante. Este passa a ser visto, então, como o meio ideal e mais imediato para intervenções, a cavidade hospedeira onde, por um período prolongado de nove meses, o embrião se aloja, e é ali, portanto, que deveriam começar os cuidados. Essas afirmações destacam a importância da vida intra-uterina e a ideia de que grande parte da saúde do sujeito adulto é preparada, de modo particular, durante a gravidez.

Rohden (2003) sublinha que a medicina, antes do século $\mathrm{XIX}$, pouco se referia às gestantes e aos cuidados que deveriam ser adotados durante a gravidez. Foi aos poucos que mulheres gestantes passaram a ser responsabilizadas pelos altos índices de mortalidade infantil, em razão de seu desconhecimento dos princípios da reprodução, da gravidez e da saúde dos recémnascidos.

Odent (2002) assinala que a ideia de "que a saúde é, em grande parte, formada no útero" abre todo um campo de medicalização da gravidez e da primeira infância que recai obsessivamente sobre o corpo da mãe. A partir de então, é a mãe - a progenitora - a pessoa adequada para garantir a saúde da criança, enquanto anteriormente poderiam ser as amas e outras mulheres. Acentua-se a legitimidade da maternidade biológica através da centralidade outorgada ao corpo da mãe como condicionante da saúde do/a filho/a. Essa ressignificação teve profundos efeitos nas concepções e políticas em torno da maternidade, de modo que a sociedade ocidental não se desprende dos laços biológicos até hoje - aliás, parece que os está sempre renovando.

Nesse contexto, nos discursos da puericultura intra-útero, o feto passa a ser apresentado como necessitando de proteção não 
apenas das "mãos superzelosas" e das autoridades de saúde, mas especialmente do corpo da própria mulher, $e$ isso traz consequências diretas para as mulheres que engravidam, o que leva alguns/mas autores/as a afirmar, hoje, que:

a reprodução não é um fato biológico atemporal - a biologia já não pretende existir fora da história; ao contrário, observa-se o uso ideológico da biologia. Em nossa cultura ocidental, as fronteiras entre natureza $e$ cultura ainda são fortemente policiadas, o que tem estreita relação com a exploração da mulher/mãe (Aunger, 2001:19).

Da perspectiva de Scavone (2001:136), os discursos técnicocientíficos, em especial da puericultura intrauterina ${ }^{3}$, contribuíram para redimensionar e (re)significar as práticas sociais da maternidade, produzindo sujeitos generificados sob os pontos de vista político e social. Na mesma direção, concordamos com Badinter (1985:116) ao afirmar que “(...) os valores de uma sociedade são por vezes tão imperiosos que têm um peso incalculável sobre os nossos desejos (...) e sobre os nossos ventres". Essas razões, dentre outras, indicam a pertinência de dialogarmos sobre os cuidados corporais e sobre como se processam, entre nós, algumas das aprendizagens que (con)formam corpos grávidos, marcando fortemente as mulheres,

3 Estudiosas e ativistas, como Sonia Correa, Lucila Scavone, Margarete Arilha e Dagmar Meyer, chamam-nos a atenção para o fato de que as políticas públicas de saúde privilegiam o ciclo gravídico-puerperal, legitimando e exaltando a capacidade reprodutiva da mulher. Observa-se que a assistência pública em relação à saúde da mulher, no Brasil, sempre esteve voltada, de um modo geral, para os programas relacionados com reprodução, controle de natalidade, planejamento familiar, saúde reprodutiva e saúde materno-infantil. Dagmar Meyer (2004:90) avalia que a maioria dos programas que compõem as políticas de atenção à saúde da mulher, na atualidade, pretende ampliar "(...) a noção de saúde da mulher para além de sua ênfase na reprodução da espécie. Apesar dessas pretensões, a redução das noções de mulher à noção de mãe, e de saúde da mulher à dimensão de saúde do aparelho feminino [continua sendo] um processo bastante ativo nesses programas". 
Discursos que (con)formam corpos grávidos

tanto as mulheres-gestantes que contrariam as normas $e$ a sacralidade da maternidade, quanto aquelas que as aceitam.

E é a perspectiva de gênero que se aproxima das teorizações foucaultianas que, entre outras, tem nos permitido problematizar a maneira como os cuidados com os corpos grávidos sofreram $e$ sofrem modificações em relação ao tempo. Mudanças que parecem sugerir uma visão renovada do lugar do corpo materno, que cada vez mais se desloca, contemporaneamente, de um lugar de preservação da espécie para o de aperfeiçoamento físico e moral da espécie.

É com essas referências teóricas que identificamos um processo de politização da gravidez que não só prossegue seu curso contemporaneamente, mas se complexifica e se expande. Nesse movimento, o processo de gestação, que em outros tempos era um tema da esfera privada, muda de lugar, atingindo o amplo grupo social - ele não está mais restrito apenas ao grupo familiar/cônjuges. Assim, ao longo do século XX, também no contexto brasileiro, multiplicaram-se discursos e representações sobre a gravidez reforçando a ideia da centralidade da mulher no processo gestacional. Isso se dá nos Estados modernos, a partir da expansão das políticas de saúde, por meio do "imperialismo moral" (Luz, 2003) do discurso médico e do aparecimento de outros diferentes discursos voltados ao cuidado da saúde materno-infantil, principalmente os enfatizados pela mídia ${ }^{4}$ (em sentido amplo). Daí a necessidade de interrogar-se sobre esses "novos" sentidos da politização dos corpos grávidos na contemporaneidade. Encaminhamo-nos, então, na direção de responder à seguinte pergunta: que politização se desenha nesse horizonte? $\mathrm{E}$, assim, surge nosso interesse pela problemática da

4 No Brasil, encontramos uma grande gama de materiais - jornais, manuais, programas de TV, propagandas, revistas e, mais recentemente, sites endereçados às mulheres mães. Entendemos que esses materiais têm um papel central no movimento moral de educação sobre os corpos de grande parte das mulheres gestantes no Brasil. 
politização da maternidade $e^{5}$, nesta investigação em particular, pela politização dos corpos grávidos no contexto de um artefato específico da mídia impressa brasileira, a revista Pais \& Filhos.

Examinamos exemplares ${ }^{6}$ da revista publicados no período de 1968 a 2005, perfazendo um total de 674 revistas. A demarcação temporal da investigação levou em conta o tempo da revista no mercado brasileiro, ou seja, 37 anos. Isso nos permitiu dar conta da análise das quase quatro décadas de existência da publicação. Procuramos garantir ao menos duas a três edições de cada ano de publicação desde o lançamento da Pais \& Filhos. Uma vez que cada época diz o que pode dizer, conforme suas condições de enunciação e de seus campos de visibilidade (Foucault, 1998), desafiamo-nos, com esse exame, a compreender a maternidade e, sobretudo, a gravidez sob o prisma do contexto histórico.

Esse foi, então, um dos propósitos da pesquisa da qual se desdobra este artigo: historicizar alguns dos modos pelos quais determinadas maternidades foram significadas politicamente no interior de uma série de discursos - na Pais \& Filhos - que as normatizam e definem, e não como experiências "sem história", mas associando-as a uma ideia biológica, considerada como natural do feminino.

5 Esse tema vem sendo desenvolvido por Dagmar Estermann Meyer, com apoio do CNPq, desde 2000, nas seguintes pesquisas, já concluídas: Mulher perfeita tem que ter mamas e uma barriguinha: educação, saúde e produção de identidades de gênero, concluído em fevereiro de 2003; Educar e assistir corpos grávidos para gerar e criar seres humanos "saudáveis". Educação, saúde e constituição de sujeitos "de direito" e "de risco", concluído em fevereiro de 2005; A educação 'da família' como estratégia governamental de inclusão social: um estudo situado na interface dos Estudos Culturais, de Gênero e de Vulnerabilidade, concluído em fevereiro de 2008.

6 Foram localizados e examinados: 220 exemplares do período de 1968 a 1980; 102 exemplares de 1980 a 1990; e 172 exemplares do período de 1990 a 2005. 
Discursos que (con)formam corpos grávidos

\section{Mídias e educação de mulheres mães: a revista Pais \& Filhos}

Fischer (2005) é uma das estudiosas que chamam a atenção para a importância que a mídia assume na atualidade. Ocupando uma posição central no processo de constituição do sujeito contemporâneo, a mídia influencia e modifica, dentre outras coisas, modos de ser homem e mulher, incluindo os modos de ser pai, mãe e gestante.

Observa-se, hoje, uma frutífera aliança entre biopolítica e mídia. Para Vaz (2004:8), atualmente, a forma de poder predominante não é mais a vigilância, mas a informação, que adverte os indivíduos "dos riscos, dado o que fazem e o que trazem como herança". Podemos dizer que a pós-modernidade monitora os corpos através das informações, dentro daquilo que Fraga (2005:28) chamou de uma "biopolítica informacional":

(...) uma forma de governo que não depende [apenas] da relação corpo-a-corpo para fazer valer um poder sobre a vida da espécie, mas de um conjunto de técnicas, procedimentos e saberes que regulam a vida [por meio das informações].

Para Costa (2003), teorias e conhecimentos técnicocientíficos viajam por diversas topografias, "migram através de itinerários cada vez mais complexos". Ainda segundo a autora (2003:255), as "revistas fazem parte desse aparato discursivo e ocupam um lugar importante de mediadores culturais" na contemporaneidade. Dessa forma, destacamos a Pais \& Filhos como uma, dentre muitas, das tradutoras dos discursos técnicocientíficos (em especial, os de gestão e promoção da saúde) para o senso comum.

Essas incitações de discursos técnico-científicos acerca da gestão e promoção da saúde dirigidas às mulheres-gestantes são incorporadas e traduzidas para a esfera do senso comum para melhor administrar, gerir, ensinar, inserir e regular as vidas dos diferentes grupos de mulheres gestantes. Para Pinto (1989:44), no 
interior desse conjunto articulado de fragmentos discursivos é possível localizar o discurso científico dentro do senso comum, de modo que, neste último, "a" ciência aparece como sinônimo "de saber e de autoridade". É nessa direção que procuramos entender como a Pais \& Filhos (re)cria, reduplica e faz circular significados em relação aos cuidados com os corpos de mulheres gestantes.

Fischer (2005) afirma que a mídia, tanto a escrita quanto a falada, mais do que inventar ou produzir um discurso, o reduplica sempre a seu modo, na sua linguagem, "na forma de tratar aquilo que 'deve' ser visto e ouvido". Para a autora, a mídia constitui-se em um importante espaço de "reduplicações dos discursos, dos enunciados de uma época" (Fischer, 2006:85).

No contexto da mídia brasileira direcionada à família e, sobretudo, às mulheres (potencialmente) mães, ressaltamos a importância da Pais \& Filhos, uma vez que essa publicação é tida como "a mais tradicional revista da família brasileira, há trinta e sete anos no mercado" (Mira, 2001). A revista desfruta de uma longevidade notável, comparada com a quantidade considerável de revistas lançadas, para esse público, a cada ano no Brasil ${ }^{7}$, ainda mais se considerarmos que poucas delas conseguem passar pela prova dos dez anos da primeira publicação.

Segundo Mira (2001), a Pais \& Filhos é identificada como a primeira publicação brasileira (1968) a discutir, por exemplo, a educação de crianças e a mostrar a necessidade de pais e mães planejarem a chegada de seus/suas filhos/as. Das revistas destinadas a pais e mães, a Pais \& Filhos é a revista brasileira de maior tiragem, sendo considerada como uma das publicações mais lidas por esse segmento, principalmente no âmbito das chamadas classes médias.

O público leitor da Pais \& Filhos é composto, majoritariamente, por mulheres adultas de todas as classes sociais,

7 Gravidez Feliz, Gravidez Especial, Gravidez e Gestação, Supermãe, Da Concepção ao Nascimento, A Gestação, Ser Mãe Especial, Seu filho e Você, Crescer em Família. 
Discursos que (con)formam corpos grávidos

embora haja prevalência das de classes média e alta, escolarizadas e com renda própria. Conforme dados do conselho editorial ${ }^{8}$, o universo dos/as leitores/as da Pais \& Filhos é composto, principalmente, por pessoas na faixa etária entre 20 e 49 anos, sendo $82 \%$ do sexo feminino e $18 \%$ do sexo masculino.

Para examinar a revista, apoiamo-nos na perspectiva dos Estudos de Gênero e dos Estudos Culturais que se aproximam das teorizações pós-estruturalistas e utilizamos, como estratégia metodológica, a análise de discurso foucaultiana. Consideramos a Pais \& Filhos (seus textos e imagens) como um artefato cultural inserido em uma cadeia de artefatos culturais de diferentes tipos; exatamente por isso, o que nela se diz (e também o que se silencia) tem repercussões sociais, políticas e históricas.

Do ponto de vista da metodologia adotada, realizamos as análises valendo-nos das contribuições de Foucault (1989) no que tange ao conceito de discurso e enunciado. Foucault sugere que o/a pesquisador/a tome os discursos em sua materialidade $e$ tensione suas condições de produção $e$ as posições de sujeito neles descritas. Instrumentalizadas por esse "modo de ver", optamos por mapear os enunciados nos discursos da Pais \& Filhos, observando as suas regularidades, insistências, repetições, possíveis rupturas e descontinuidades.

Passamos, pois, a destacar aqui alguns dos cuidados corporais através dos quais a Pais \& Filhos nos educa como sujeitos de gênero, entendendo que educar mulheres grávidas, com foco em seus corpos, está dentro desses processos que nos educam como mulheres, uma vez que essas aprendizagens nos ensinam, nesse caso, a conferir sentido à gravidez $e$ à maternidade, num processo que não é linear, nem homogêneo, tampouco está acabado e completo (Meyer, 2003). Consideramos também que, de um modo geral, não se reconhece a dimensão do trabalho que está contido nas exigências que se fazem às mulheres

8 Esses dados fornecidos pela editora foram extraídos de uma testagem de mercado (em mil pessoas) pelos estudos Marplan, 2003. 
durante a gestação. Por isso, entendemos ser pertinente mostrar um pouco desse trabalho, que, a nosso ver, vem alcançando graus cada vez mais elaborados e complexos nas culturas contemporâneas ocidentais.

\section{Os discursos da medicina à educação física}

Observamos, na revista ${ }^{9}$, um movimento que nos apresenta, em uma "nova" história, formas de relacionamento e gerenciamento de corpos na gravidez. Um dos efeitos da estratégia de investimentos nos corpos grávidos elaborada pela revista é a definição de diferentes posições de sujeito, pois estar gestante $e$ tornar-se mãe não é, nesse contexto, a mesma coisa que ser mulher. É possivel afirmar que a Pais \& Filhos faz um declarado movimento no sentido de posicionar a mulher gestante, diferenciando-a da posição de sujeito mulher. Encontramos também muitos exemplos do modo como a Pais \& Filhos educa as mulheres para almejarem o estado de gravidez, como se pode ler na capa de um dos números da revista: “(...) GRAVIDEZ: um estado de graça, um momento de mais pura alegria, uma condição que deixa a mulher com mais inteligência" (Pais \& Filhos, 1977:capa).

Destacamos este excerto com o objetivo de visibilizar que grande parte do projeto editorial da revista parece contribuir para fortalecer uma representação de gestante feliz e, de certo modo, deslumbrada com a gravidez. Os enunciados "(...) é maravilhoso ter filhos..." e "estar grávida (...)", destacados pela Pais \& Filhos, são exemplares das muitas estratégias que reiteram, renovando, uma imagem de felicidade e de celebração do processo de gravidez. É suposto pela revista que "as mulheres sente[m]-se

9 Muitos dos fragmentos de discursos destacados ao longo desta seção foram retirados da Pais \& Filhos. Nosso olhar para a revista, nesse momento, deteve-se nos temas que tratam da gestão do corpo das gestantes, modos de cuidar, de comportar-se. Destacaremos aqueles que, no contexto da revista, se estabelecem como prescrições mais regulares. 
Discursos que (con)formam corpos grávidos

felicíssimas com a gravidez". Mas será mesmo que todas as mulheres acham maravilhoso fazer uma série de exames e passar pela inspeção de um grande número de profissionais da saúde periodicamente? Que todas as mulheres acham maravilhoso viver, durante os nove meses da gestação, com um ser dentro do seu corpo, que depende inteiramente delas? Para muitas de nós, estas perguntas evocam não apenas maravilhas ou instantes de felicidade arrebatadora, mas também muitos momentos de "angústias", medos, preocupações. A partir do momento em que se sabe que se está grávida, há uma série de novos aspectos sobre a vida que aprendemos a pensar, incluindo a ideia de que nunca mais se será "livre" (mesmo que assumamos a impossibilidade de uma liberdade não contingenciada em qualquer contexto $e$ situação). Isso, por vezes, é bastante difícil de aceitar, e leva-se tempo para equacionar a relação consigo e com os outros em termos sociais e emocionais. Entretanto, essas questões são pouco debatidas pela revista.

Outra estratégia de positivação da gravidez, na revista, envolve o pequeno número de reportagens que discorrem e/ou informam sobre desconfortos que podem ocorrer durante o período de gestação, como náusea e sonolência; quando são mencionados tais desconfortos, apresentam-se logo possíveis soluções, produtos e recursos que podem minimizá-los, assegurando o retorno a um estado de bem-estar da gestante. Assim, constrói-se na Pais \& Filhos a crença em uma maternidade controlada, que é incrementada pelo emprego, cada vez mais abrangente, de prescrições que vão desde atividades físicas até remédios - como analgésicos e tranquilizantes - para eliminar desconfortos na gravidez.

Nessa direção, afirmamos que a noção de mulher-mãegestante com a qual a revista parece operar é a de um ser que incorpora múltiplos seres e que neles se (des)faz. Isso ocorre quando a revista recomenda, por exemplo, que as gestantes sejam, ao mesmo tempo, nutricionistas, psicólogas, esteticistas e especialistas em desenvolvimento fetal e que façam consultas $e$ 
exames médicos regularmente durante a gravidez. ${ }^{10}$ Elas são desafiadas a colocar seus corpos (e os cuidados corporais a eles relacionados) à frente de qualquer outra necessidade. Em movimentos como esse, vemos desenhar-se, nas páginas da Pais \& Filhos, uma imagem de mãe com características de mulherativa-com-um-corpo-bem-cuidado, instigada a fazer o melhor de si por si mesma.

De modo geral e de maneira muito direta, leitoras e leitores da revista convivem com o princípio de que um corpo grávido "deve" ser cuidado e "aperfeiçoado" (Pais \& Filhos, 2007:18). Nessa perspectiva, observa-se que a gravidez vai sendo definida, ao longo do projeto editorial da revista, como uma condição devidamente "controlada, regulada, plena de temperança, prudência, gestão criteriosa/ponderada dos riscos" (Pais \& Filhos, 2007:14). Ao contrário das "antigas" mães, que, segundo Scavone (2004), "mal tomavam conhecimento" dos seus corpos e dos cuidados com filhos/as, as "novas" mães, sobretudo as de classe média $^{11}$, têm sido as maiores consumidoras dos discursos de perfectibilidade física dos corpos. A contemporaneidade deixa de ser o tempo - especialmente para as mulheres - de descuido com os corpos, para ser um tempo protocolar de correções físicas da aparência e da saúde.

Scavone (2004) destaca que os discursos de completo bemestar físico, mental e social oriundos do próprio conceito da OMS e

${ }^{10}$ Para Hays (1998), a entrada de muitas mães de classe média no mercado de trabalho parece ter contribuído para a lógica de que as mães devem ser educadas para a maternidade e de que só os/as especialistas podem proporcionar a sua educação/orientação.

${ }^{11}$ As mães de hoje, sobretudo as de classe média, são essas mulheres que conhecemos bem, que investem na pessoa de seus/suas filhos/as, preocupadas com seu futuro. Por exemplo, é muito comum observarmos a predominância de mulheres em reuniões escolares, nos diferentes fóruns de discussão da família, em painéis integrativos, grupos de reflexão, reuniões de consultoria, terapias familiares, clínicas de saúde, academias. As mulheres mostram-se sempre mais abertas para debaterem as mudanças da estrutura e do comportamento familiar, bem como as suas consequências (Hays, 1998). 
Discursos que (con)formam corpos grávidos

(re)afirmados particularmente pela medicina americana mudaram o perfil dos modos de nos relacionarmos com os corpos e com a saúde. Segundo a autora, observa-se claramente que a saúde materna também se inspirou nessa enunciação da OMS, principalmente na do completo bem-estar. Esse conceito de saúde tem como referência um modelo de saúde idealizado - a saúde perfeita - a ser alcançado, cujas características holísticas (a completude inatingível) servem como padrão também para definir aspectos específicos da saúde materna. Tal representação sustenta a existência de um estado ótimo de saúde como critério de avaliação dessa saúde materna. Nessa perspectiva, a condição de pleno "bem-estar" seria assegurada somente através do uso adequado dos recursos das ciências.

Entendemos que pressupostos como esses produzem efeitos na educação $e$ regulação das grávidas na atualidade, redimensionando a relação corpo $\mathrm{X}$ gestante $\mathrm{X}$ feto, ao mesmo tempo em que ensinam às gestantes, conforme Virilio (1996:97), que a saúde "não apenas é algo que se tem, mas que constantemente é preciso adquirir" e aperfeiçoar antes, durante $e$ depois da gravidez.

Nas páginas da revista, fala-se muito da condução de uma gravidez "planejada". Destacamos que a crença de que uma gravidez pode ser - e deveria ser - rigorosamente planejada acaba por exigir das mulheres-gestantes - e só de cada uma delas - um engajamento individualizado, principalmente com o dever de ter, controlar, promover, aperfeiçoar a saúde. Isso implica posicionar na esfera individual a responsabilidade pelos meios e recursos necessários para a viabilização do projeto de corpo (o da gestante e o do feto) e de saúde da sociedade, como observa Meyer (2002:3). Desse modo, vemos que as gestantes ${ }^{12}$ são chamadas pela revista para

\footnotetext{
${ }^{12}$ Lupton (1999) observa que os discursos e as estratégias de promoção da saúde (pública e particular), dirigidos às grávidas, não são capazes de interpelar todas elas ao mesmo tempo ou do mesmo modo.
} 
administrar seus riscos, numa forma de autopoliciamento privado que implica o dever de lutar contra o próprio destino, ultrapassando os limites da própria configuração biológica com a ajuda da tecnociência [para alcançar] o imperativo da saúde controlada/perfeita, no campo da procriação, na tentativa de evitar que erros inscritos como probabilidades nos códigos genéticos se efetivem - tanto nos organismos quanto no corpo social (Sibilia, 2004:199).

O "inimigo" número um de uma gravidez saudável, que aparece nos múltiplos discursos veiculados pela Pais \& Filhos, é o próprio corpo das gestantes ${ }^{13}$, pois é ele que é preciso "limpar, desalojar, evidenciar, analisar, vencer" (Sfez, 1995:179). O fato de a mulher estar grávida modifica, quase completamente, o olhar que se tem sobre o seu corpo, o que se pode ver, por exemplo, quando a Pais \& Filhos afirma, já na década de 70, que "cada gestante deve aprender a decodificar, incessantemente, as linguagens de um organismo grávido, valendo-se, para isso, do pré-natal" ${ }^{14}$ (Pais \& Filhos, 1974:35). Nesse sentido, o que se pode dizer é que, na primeira década de publicação da revista (1968 a 1980), os saberes oriundos do discurso médico respondiam, de forma quase absoluta, pelo pré-natal. A revista multiplica e faz circular o enunciado, que continua sendo constantemente atualizado e ampliado por outros discursos, de que um

\footnotetext{
${ }^{13}$ Para Le Breton (2003), para certo imaginário da área da saúde, há um medo do corpo da mulher-mãe, em especial do seu útero. O útero é considerado, por parte dessa área, como um lugar obscuro e perigoso, um ambiente precário, difícil de controlar e regular. É nessa direção que alguns pesquisadores do domínio da reprodução acham que, se o desenvolvimento do feto ocorresse numa matriz artificial, isso garantiria um ambiente muito mais confiável $e$ permitiria efetuar correções e modificações genéticas muito mais facilmente.

${ }^{14}$ No Brasil, o Ministério da Saúde preconiza a realização de, no mínimo, seis consultas de acompanhamento pré-natal: preferencialmente, uma no primeiro trimestre, duas no segundo e três no terceiro trimestre de gestação.
} 
Discursos que (con)formam corpos grávidos

bom pré-natal é a linha divisória entre a vida e a morte, a saúde $e$ a doença, a normalidade $e$ a anormalidade, [e] o que interessa é que isso é dito às mulheres, freqüentemente, e que são elas que precisam cuidar de seus corpos grávidos e dos corpos de seus filhos (Ripoll, 2005:66).

O pré-natal surge articulando as perspectivas de uma puericultura intra-útero com a de saúde materno-infantil. Consiste em um acompanhamento multidisciplinar, sistemático e regular da gestante pelos profissionais da saúde durante os nove meses. Esse acompanhamento é feito por meio de consultas médicas, exames laboratoriais (diabetes, anemia, hepatite, HIV e muitos outros), exames físicos (verificação de pressão arterial e peso, ausculta dos batimentos fetais do bebê, palpação e medição do útero, exames das mamas, pernas, tornozelos, mãos) e reuniões educativas, em grupo ou individuais, para ensinar a cuidar das mamas, a amamentar corretamente, a reconhecer as fases e etapas de desenvolvimento infantil, as vantagens do parto natural, etc. Os dados (resultados) de cada consulta são registrados na carteira $e$ no cartão da gestante. Entendemos que a carteira (assim como as fichas, os cartões e os protocolos) das gestantes

(...) indica[m] bem a aparição de uma nova modalidade de poder em que cada um recebe como status sua própria individualidade, (...) estatutariamente ligado aos traços, às medidas, aos desvios, às notas que o caracterizam e fazem, de qualquer modo, um "caso" (Foucault, 1977:171).

As fichas, os exames ou os registros funcionam como estratégia política para tornar visível um determinado tipo de corpo e fazer a gestante estreitar o contato com esse corpo $e$ principalmente com o do feto para perceber as próprias condições físicas, acompanhá-las, controlá-las e, de preferência, estendê-las ao infinito. Le Breton (2003:95) destaca que “(...) os exames, as fichas, desenvolvem uma forma sutil de higienismo e eugenismo de Estado, do qual somos herdeiras/os". Nessa perspectiva, os 
exames do pré-natal captam, fixam detalhes e minúcias da vida das gestantes $e$, sobretudo, do seu corpo $e$ do feto em gestação $e$ assim capturam as necessidades de ambos e as traduzem de forma a homogeneizar esses corpos mediante um código de sinais $e$ sintomas. Ao colocar gestante e feto num campo de vigilância, o exame situa ambos, igualmente, numa rede de anotações escritas; assim, "(...) um poder de escrita é constituído como peça essencial nas engrenagens da disciplina" (Foucault, 1977:168).

Além do controle da saúde das gestantes, observa-se o interesse destacado da revista na avaliação dos recém-nascidos. Encontramos um volume de artigos que descrevem minuciosamente que os primeiros minutos após o nascimento do bebê devem ser destinados a uma série de testes e cuidados: a criança é pesada, medida (corpo, tórax, cabeça), verifica-se a sua temperatura, frequência cardíaca, respiração, cor e consistência da pele, e quase todos os seus órgãos são examinados minuciosamente. Além disso, depois do exame clínico, o recémnascido é submetido a testes neurológicos.

Essa avaliação descrita na Pais \& Filhos é feita através da escala americana de Virgínia Apgar - método mais usado entre os médicos -, que atribui notas de 1 até 10 , de acordo com as reações do recém-nascido. A revista chama atenção que, quanto maior for essa nota, maior o mérito da mãe. A aprovação do feto apresenta-se como prova concreta de valoração da mãe, $e$ as notas atribuídas ao recém-nascido são inseridas em sua ficha. Entendemos a divulgação e explicação minuciosa desses testes como sendo mais uma estratégia da revista para reforçar a posição $e$ a responsabilidade moral das mulheres que gestam.

É possível dizer que, a partir de 1990, a discussão sobre a saúde do feto alcançou um nível de detalhamento sem precedentes nas páginas da Pais \& Filhos, devido à introdução de inúmeros artigos sobre o desenvolvimento e o uso de novas tecnologias, tais como o ultrassom e a amniocentese. Tais tecnologias possibilitaram a visualização $e$ a individualização do 
Discursos que (con)formam corpos grávidos

feto, separando-o precocemente ${ }^{15}$ da mãe. $O$ feto, a partir dessas inovações tecnológicas, saiu do domínio da experiência privada para o domínio público, passando a ser objeto de visualização, externalização, vigilância, regulação (Lupton, 1999). Meyer e Soares (2004:10) observam que, nas culturas ocularcêntricas, as diversas tecnologias científicas, através das técnicas de observações e registros, ajudam de um modo especial a "(...) instituir e promover determinadas posições de sujeito como adequadas em oposição a outras, consideradas impróprias $e$ desviantes". Entendemos que as imagens das ecografias, na revista, não se apresentam apenas como recurso técnico visual, dando também respostas a questões ligadas ao que Louro (2004) denomina de códigos identitários, pois, ao observar-se o feto, avaliá-lo, medi-lo, classificá-lo, produzem-se divisões, distinções e, sobretudo, nomeações de gênero. Trata-se de um processo duplo que classifica mãe e feto, porque inscreve marcas nos dois corpos: anormais/normais, saudáveis/doentes, negligenciados/cuidados.

A Pais \& Filhos incita-nos a pensar em uma dupla $e$ concomitante operação: uma que entroniza as mães em sua missão sagrada de gestar, e outra que ameaça as que fracassam na sua função de gerar filhos/as perfeitos/as e saudáveis. Temos muitos exemplos de como a revista exalta as mulheres que têm gravidez múltipla, por inseminação assistida ou não, porém poucos destacam os inúmeros insucessos enfrentados, os preços nem sempre acessíveis de tais técnicas, os efeitos colaterais da ingesta maciça de hormônios, os grandes sacrifícios afetivos $e$ emocionais a que são submetidas às mulheres durante a gravidez e depois do nascimento dos/as filhos/as. A revista também apresenta muitos exemplos de nascimentos de crianças com anomalias, associando-os, com muita frequência, a certo fracasso do corpo, especialmente do corpo feminino. Condenam-se,

${ }^{15}$ A foto (a gravação) da ultrassonografia materializa a existência do feto e já faz os futuros pais apresentarem a imagem não apenas como sendo do feto, mas como o "Pedrinho" dentro da barriga da mãe. Assim, a cultura é que demarca e atualiza a construção do feto como um sujeito pleno, inclusive de direitos. 
constantemente, as mães que não conseguem amamentar, sem contar as que desenvolvem depressão pós-parto. Por outro lado, há pouca divulgação de artigos afirmando

que as chances de adoecimento mental são maiores no processo de maternidade do que em qualquer outra fase da vida da mulher. A gestação exige capacidade de adaptação às mudanças físicas, psicológicas e socioculturais (Resende, 1996:435).

Além disso, encontramos orientações mais contundentes que, a partir de 1990, ilustram a pressão sobre as mulheres para mudarem seu estilo de vida quando grávidas, de modo que seus "corpos se tornem limpos" (Pais \& Filhos, 1990:14). Perguntamos: será que não acontece nada de político aí? Parece-nos que essas exigências dizem muito sobre o que se concebe como sendo a saúde moral de uma época e retomam ideias de vigilância higienista, agora mais centradas sobre si. Sibilia (2004) diz tratar-se de uma clara transição para as intervenções de uma vontade fáustica ${ }^{16}$ (limpar, corrigir, criar, ultrapassar) de "deletar" toda $e$ qualquer impureza, inclusive as da pele. Na mesma direção, Sant' Anna (2005) vê o contexto contemporâneo como uma busca da otimização da saúde pela auto-vigilância, de redramatização da relação com o próprio corpo - trata-se, agora, de mudar os comportamentos em relação às condutas individuais, de dar prova de "boa" observância e de otimização de si.

Também a partir de 1990, são comuns enunciados que convocam para práticas de prevenção. Multiplicam-se, por exemplo, textos como o que segue, sugerindo um pedido do feto à sua mãe: "Mamãe, por favor, se quiseres me ter na tua barriga, se abstenha do álcool no mínimo seis meses antes de engravidar" (Pais \& Filhos, 2002:14).

${ }^{16}$ Fáustico, para Sibilia (2004), seria o sujeito insatisfeito com a estreiteza do seu conhecimento. 
Discursos que (con)formam corpos grávidos

A ideia de gerir o corpo, mesmo antes da gravidez, para conservá-lo em boa saúde e em bom estado não é nova; no entanto, entendemos como novo o lugar ocupado pela prevenção nas práticas de saúde: trata-se de prevenir, de intervir antes do aparecimento das situações críticas, mudar hábitos $e$ comportamento em relação a condutas chamadas "de risco"; assim, a revista pretende ensinar a projetar e a controlar o futuro. Para Lipovetsky (2007:239), o objetivo é

inquietar as pessoas antes do aparecimento dos sintomas. Não a preocupação de libertar-se de si, mas ocupar-se incansavelmente com o corpo, a saúde, a forma: não fundir-se em comunidade, mas mudar seus comportamentos a fim de retardar os efeitos da idade $e$ prevenir as doenças; não "esbanjar" a vida, mas despistar os fatores de risco, fazer exercícios de manutenção (...).

É importante destacar que a maneira como os trabalhos corporais são lidos e explicados varia de época para época, não só quanto às representações produzidas, mas especialmente quanto aos interesses políticos, morais, sociais e culturais que os movem. As próprias movimentações e deslocamentos das formas de cuidados corporais que a Pais \& Filhos apresenta, ao longo de seu projeto editorial, em relação à "boa" educação da gestante mostram essas variações.

Outro discurso, alargado nas páginas da Pais \& Filhos é o da nutrição, que destaca um ideal de corpo magro, definido esculturalmente, mesmo quando grávido. Chamadas como essa são comuns e intensificam-se, desde meados de 1985, para as gestantes: "Procure uma nutricionista; coma adequadamente; você não pode ganhar peso. Você não pode comer à vontade; você não precisa comer por dois" (Pais \& Filhos, 2003:30).

Dessa forma, a ênfase recai, hoje, no controle dos corpos grávidos também pelos hábitos alimentares, e a moral do bem comer surge como forma de controle e regulação desses corpos. 
Até o antigo ritual de satisfazer os súbitos "desejos alimentares" das grávidas, que muitas vezes se manifestavam nos horários mais inconvenientes, vem sendo criticado pelo discurso da nutrição, replicado especialmente na Pais \& Filhos a partir de 1985. Muitas reportagens e chamadas sugerem que o aumento de peso durante a gestação seja, no máximo, de seis a nove quilos ${ }^{17}$, enquanto que anteriormente a 1980 uma gestante poderia engordar até 12 quilos $e$, se engordasse mais de 20 quilos, isso não seria considerado um grande problema.

Para Remaury (2002), a magreza está inscrita no campo patogênico mais amplo do século XX, quase como uma obsessão purgativa de esvaziar os corpos. Para o autor, essa obsessão purgativa faz-se notar em tudo aquilo que aumenta o corpo feminino - e a gravidez, certamente, é uma dessas coisas. Nesse sentido, vale destacar um alerta da Pais \& Filhos: o de que, nos tempos atuais, é imperdoável que a gravidez faça com que a mulher perca a silhueta - "(...) a mulher deve manter-se com um corpo magro para mostrar-se, sobretudo, para as filhas quando crescidas" (Pais \& Filhos, 2003:30).

Parece que conservar-se magra é positivado, com mais intensidade, a partir de 1995 no projeto editorial da revista em qualquer situação, inclusive durante a gravidez. Estar magra é uma moeda eficaz de trocas, uma forma de interação inclusive entre as gerações (mães e filhas), um modo de sociabilidade, como destaca Edmonds (2002). Para o autor, parece que hoje se posicionam os corpos

de mães e filhas em um novo contexto comparativo $e$ unificador - posiciona-se, assim, o peso como mais um instrumento homogeneizador das diferenças entre as gerações (Edmonds, 2002:209).

${ }^{17}$ Esses dados também se encontram disponíveis no Manual de Obstetrícia (Resende, 2002). 
Discursos que (con)formam corpos grávidos

Também os novos arranjos familiares ${ }^{18}$ parecem servir de solo fértil para os cuidados dos corpos prosperarem. Na revista, observamos um movimento em que se exige que as mães mantenham seus corpos em termos de peso, por exemplo, semelhantes aos de suas filhas adolescentes. A revista destaca um dos grandes trunfos que mães que cuidam com afinco de seu corpo têm: o de parecerem jovens. Não basta ser uma boa mãe, dedicada e competente; é preciso envelhecer "enxuta", para que essa posição seja mais valorizada socialmente, como destaca a Pais \& Filhos (2004:44).

Parece-nos que, na esteira do imperativo da magreza, a gestante leve e a valorização social da gestante ativa ecoam na vida das grávidas de hoje, de modo que os cuidados corporais veiculados pelos programas regulares de exercícios físicos não ficaram fora do processo de regulação dos corpos grávidos veiculado pela Pais \& Filhos. Os exercícios estão nas prescrições que compõem as orientações do pré-natal no contexto da revista $^{19}$, embora essa indicação não tenha aparecido com a mesma constância ao longo do tempo. Falar de programas regulares de práticas corporais para mulheres, no caso, mulheres no período pré-natal, é falar "de um lento processo civilizatório, da lenta e complexa mudança de sensibilidade, da tolerância ou intolerância por atitudes", como observa Soares (2004:5). Imperativos como os que seguem foram se fazendo cada vez mais presentes nas páginas da revista:

A gestante precisa de cuidados especiais no decorrer desses nove meses $e$ isso se aplica às atividades corporais.

\footnotetext{
18 Para Edmonds (2002), questões como a democratização da beleza, a crescente igualdade na competição feminina entre gerações diferentes no mercado afetivosexual e a mobilidade social associada à construção de uma identidade baseada no corpo contribuíram para a deflagração desses processos, no Brasil.

${ }^{19}$ Ver Martins (ano???). O autor afirma que atualmente o trabalho com as gestantes se constitui para os profissionais de educação física como fatia de mercado profissional bem representativa.
} 
Grávida! [Faça] Muitos exercícios - Livre-se dos tabus e garanta o seu bem-estar e o do seu filho (Pais \& Filhos, 2002:45).

Soares (2003:10) instiga-nos a considerar que, nos últimos 200 anos, no mundo ocidental, se tem afirmado "uma cultura do movimento", sustentada pela ciência e pela tecnologia, sobrepondo-se aos indivíduos, aos grupos e às diferentes classes sociais, como prática importante de cuidado que (re)define seus objetivos como uma prática indispensável à saúde. ${ }^{20}$ Como bem observa a autora, parece que hoje há uma tentativa de convencimento "da necessidade imperiosa de colocar o corpo em movimento, sem o que não há saúde" (id.). Além disso, é interessante destacar que práticas corporais, de modo geral, até o início do século XX, eram consideradas atitudes prejudiciais não condizentes com a gravidez e, por isso, eram desaconselhadas. Acreditava-se que as atividades corporais provocariam abortos $e$ roubariam oxigênio do bebê. As gestantes deveriam fazer repouso.

Entre os discursos e as intervenções destinados a educar os corpos grávidos, o esporte, como prática contemporânea, também faz parte dessa educação. Não é à toa que uma variedade dessas práticas para as gestantes eclode com mais força no projeto editorial da Pais \& Filhos a partir da década de 80, garantindo-se como prática importante de cuidado de si.

O enunciado "a gestante deve se movimentar" (Pais \& Filhos, 1980:capa) multiplica-se na revista em uma quantidade de artigos no sentido de reafirmar a importância das práticas de atividades corporais alternativas para as gestantes em chamadas como:

${ }^{20} \mathrm{O}$ uso dessa expressão é retomado porque, como observa Soares, se analisarmos o processo histórico da educação física no Brasil, perceberemos que esse tipo de legitimação das práticas corporais é bastante antigo. Soares (1994) afirma que as primeiras tentativas de incluir a educação física no universo escolar foram em nome da promoção da saúde, da higiene física e mental e da educação moral e eugênica. A autora acrescenta que o sentido do conceito de saúde não ficou estático, modificando-se de acordo com as condições históricas. 
Discursos que (con)formam corpos grávidos

Grávida! Entregue-se às atividades esportivas (Pais \& Filhos, 1981:19) [ou ainda] Para manter-se saudável e bem disposta durante toda a gestação, nada melhor do que deixar de lado a preguiça e fazer atividades físicas (Pais \& Filhos, 1980:19).

Essas chamadas sinalizam e destacam a necessidade de as grávidas realizarem atividades físicas. Entretanto, não podemos deixar de pensar nos diversos significados atribuídos à expressão "práticas corporais esportivas" na cultura ocidental, como assinala Soares (2005). A imagem do/a esportista parece-nos curiosa porque joga com certa concepção do corpo forte e resistente; assim, o/a esportista

é quase sempre movido pela ideia de ir mais longe, ser mais veloz, fazer a ultrapassagem dos limites das próprias forças, de regular os esforços (...), de superação de si mesmo (Soares, 2005:52).

Se, de um lado, o esporte faz uma referência ao rendimento extremo, à competitividade máxima e à extrapolação de limites, de outro, associa-se à ideia de um trabalho de aprendizagem do espírito de equipe, cooperação, negociação e mesmo de superação individual (Soares, 2005). As práticas corporais justificam-se para as gestantes, em princípio, também na esteira dessa perspectiva moral, como oportunidade para interação social. Nessa direção, elas são repolitizadas enquanto metáfora de "cooperação entre os corpos mãe e filho/a", num contexto como o da Pais \& Filhos, em que esse vínculo - enunciado na noção da mãe cuidadosa - é um valor moral positivo.

A partir desses discursos - do pré-natal, da medicina, das tecnologias, da nutrição, da educação física, da estética desencadeadores de aprendizagens corporais é possível fazer referência a uma nova politização da maternidade: 
nova não no sentido de inovadora, mas no sentido de uma atualização, exacerbação, complexificação e multiplicação de investimentos educativo-assistenciais que têm como foco as mulheres (...) [no caso, as gestantes] (Meyer, 2004:16).

Assim, a pesquisa e, especialmente o recorte dela que apresentamos aqui permite dizer que o processo da gravidez está estreitamente relacionado com o de construção de gênero: educar mulheres para se tornarem e viverem como grávidas está dentro de processos que nos educam como sujeitos de gênero. Dessa forma, apoiamo-nos em um pressuposto feminista fundamental para o debate contemporâneo dos Estudos Feministas - o pessoal é também político - para explicar as relações que se estabelecem entre a produção dos sujeitos, tentando compreender também as formas como nos tornamos sujeitos de gênero - mulheres $e$ homens, mães (a boa mãe) e pais. Entretanto, cuidar do corpo quando grávida não diz respeito apenas ao controle do peso, das medidas, de ter um filho mais saudável; vale lembrar que as intervenções corporais decorrentes desse processo contemporâneo se traduzem em gratificações sociais, destacadas pela revista na identidade da boa mãe - a que cuida e se cuida. Deixar de se cuidar é interpretado pela revista como "má conduta" - indicador de negligência, mãe má, descuidada.

A mãe que não assume determinados cuidados corporais sofre importantes formas de discriminação nas sociedades que cultuam o corpo e, sobretudo, nos serviços de saúde. Nesse sentido é que observamos que, aos poucos, os cuidados corporais assumem um lugar de diferenciação, chegando a funcionar, nos dias atuais, como formas de in-exclusão. Com efeito, os cuidados corporais mostram-se como uma forma de estar preparado para enfrentar os julgamentos e as expectativas sociais. Dessa forma, os cuidados corporais na gravidez vinculam-se também à visibilidade social que a gestante deseja atingir, ou seja, evitar o olhar do outro ou a ele se expor. Os cuidados corporais apresentam-se como um aspecto importante de coação social, na medida em que definem 
Discursos que (con)formam corpos grávidos

não só as insígnias de cada gênero, como também engendram a distinção entre diferentes identidades. ${ }^{21} \mathrm{Em}$ última análise, os cuidados corporais são práticas normalizadoras e reguladoras que capacitam os indivíduos que a elas aderem a se sentirem pertencentes à normalidade.

A experiência do corpo grávido e da vivência da gestação é sempre modificada pela cultura. Como aponta Artaud (2004:43):

Meu corpo é às vezes meu, uma vez que ele porta os traços de uma história que me é própria, de uma sensibilidade que é minha, mas ele contém, também, uma dimensão que me escapa radicalmente e que o reenvia ao simbolismo de minha sociedade.

\section{Referências bibliográficas}

ARTAUD, Antonin. Van Gogh. O suicidado da sociedade. Rio de Janeiro, José Olímpio, 2004 [Tradução: Ferreira Goulart].

AUNGER, Robert. Darwinizing culture: the status of memetics as a science. Oxford, Oxford University Press, 2001.

BADINTER, Elisabeth. Um amor conquistado. O mito do amor materno. Rio de Janeiro, Nova Fronteira, 1985.

CostA, Claudia de Lima. As publicações feministas e a política transnacional da tradução: reflexões do campo. Revista Estudos Feministas, vol. 11, nº 1, Florianópolis, 2003, pp.254-264.

CosTA, Jurandir Freire. Ordem médica e norma familiar. Rio de Janeiro, Graal, 1979.

EDMONDS, Alexandre. No universo da beleza: notas de campo sobre cirurgia plástica no Rio de Janeiro. In: GOLDENBERG, Mirian. (org.) $\mathrm{Nu}$

${ }^{21}$ Identidade(s) não tomada(s) aqui como individualidade(s), nem como um processo estático (e definido), mas como processo aberto que envolve uma incessante reorganização de significados culturais, com os quais nos relacionamos nos contextos socioculturais. Assim, entendemos as identidades como múltiplas e plurais, podendo ser assumidas, ao mesmo tempo, pelos mesmos ou por diferentes atores sociais (Silva, 2000). 
\& Vestido: Dez antropólogos revelam a cultura do corpo carioca. Rio de Janeiro, Record, 2002, p.414.

FISCHER, Rosa Maria Bueno. Mídia e educação da mulher: modos de enunciar o feminino na TV. In: FUNK, Susana, WIDHOLZER, Nara. (orgs.) Gênero em discursos da mídia. Florianópolis, Editora das Mulheres, 2005, pp.245-269.

Foucault, Michel. Resumo dos Cursos do Collège de France (19701982). Rio de janeiro, Zahar, 1997.

. Microfísica do poder. Rio de Janeiro, Graal, 1989.

História da sexualidade I: a vontade de saber. Rio de Janeiro, Graal, 1988. 1977.

Vigiar e punir: nascimento da prisão. Petrópolis, Vozes,

FraGA, Alex Branco. Exercício da informação: governo dos corpos no mercado da vida ativa. Tese de Doutorado em Educação, Universidade Federal do Rio Grande do Sul, 2005.

GoELLNER, Silvana Vilodre. Mulher e esporte no Brasil: fragmento de uma história generificada. In: SIMÕES, Antônio Carlos; KNIJNIK, Jorge Dorfman. (orgs.) O mundo psicossocial da mulher no esporte, comportamento, gênero, desempenho. São Paulo, Aleph, 2004, pp.23-46.

HAYS, Sharon. Contradições Culturais da Maternidade. Rio de Janeiro, Gryphus, 1998 [Tradução: Beatriz Sidou].

Le Breton, David. Adeus Corpo. Papirus, São Paulo, 2003.

Lipovetsky, Gilles. Felicidade Paradoxal. São Paulo, Companhia das Letras, 2007.

LOURO, Guacira L. Um corpo estranho: ensaios sobre sexualidade e teoria queer. Belo Horizonte, Autêntica, 2004.

LUPTON, Deborah. Risk and the ontology pregram. In: LUPTON, D. Risk and sociocultural theory: new directions and perspectives. Cambridge/UK, University Press, 1999, pp.83-114. 
Discursos que (con)formam corpos grávidos

Luz, Madel Therezinha. Novos saberes e práticas em saúde coletiva. Estudos sobre racionalidades médicas e atividades corporais. São Paulo, Hucitec, 2003.

Medicina e ordem política brasileira: perspectivas $e$ instituições de saúde (1850-1930). Rio de Janeiro, Graal, 1982.

MARTINS, Ana Paula Vosne. Visões do feminino: a medicina da mulher nos séculos XIX. Rio de Janeiro, Fiocruz, 2004.

MEYER, Dagmar. A politização contemporânea da maternidade: construindo um argumento. Gênero, vol. 6, Niterói - RJ, Núcleo Transdisciplinar de Estudos de Gênero - NUTEG, 2006, pp.81-104.

- A educação da familia como estratégia governamental de inclusão social: um estudo situado na interface dos Estudos Culturais, de Gênero e de Vulnerabilidade. Projeto CNPQ. Porto Alegre, UFRGS/FACED, 2004.

Direitos reprodutivos e educação para o exercício da cidadania reprodutiva: perspectivas e desafios. In: FONSECA, Claudia; TERTO, Veriano; ALVES, Calef. (orgs.) Antropologia, diversidade e direitos humanos: diálogos interdisciplinares. Porto Alegre, UFRGS, 2004, pp. 87-100.

; SOARES, Rosangela. Corpo, gênero e sexualidade nas práticas escolares: um início de reflexão. In: MEYER, D. E. E.; SOARES, R. F. R. (orgs.) Corpo, gênero e sexualidade. $1^{\mathrm{a}}$ ed. Porto Alegre, Mediação, 2004, pp. 136-148.

Educar e assistir corpos grávidos para gerar e criar seres humanos "saudáveis". Educação, saúde e constituição de sujeito "de direito" e "de risco". Porto Alegre, UFRGRS/FACED, 2003. (Projeto de pesquisa).

MIRA, Maria Celeste. O leitor e a banca de revistas: a segmentação da cultura no Século XX. São Paulo, Olho D'Água/FAPESP, 2001.

ODENT, Michel. Cientificação do amor. Florianópolis, Saint Germain, 2002. 
PINTO, Celi. Foucault e as Constituições Brasileiras: quando a lepra e a peste se encontram com os nossos excluídos. Educação e Realidade, vol. 24, n 2, Porto Alegre, 1989, pp. 62-88.

REMAURY, Bruno. Le beau sexe faible. Les images du corps féminin. Paris, Grasset \& Fasquelle, 2002.

RESENDE, Jorge. Manual da Obstetrícia. Rio de Janeiro, Guanabara, 1996.

RIPOLL, Daniela. Aprender sobre a sua herança já é um começo - ou de como tornar-se geneticamente responsável. Tese de Doutorado em Educação, Universidade Federal do Rio Grande do Sul - UFRGS, 2005.

ROHDEN, Fabíola. Uma ciência da diferença: sexo e gênero na medicina da mulher. Rio de Janeiro, Fiocruz, 2003.

SANT'ANNA, Denise B. Políticas do corpo, elementos para uma história das práticas corporais. São Paulo, Estação Liberdade, 2005.

SANTOS, Lucinete. Adoção: da maternidade à maternagem - uma crítica ao mito do amor materno. Revista Serviço Social \& Sociedade, $\mathrm{n}^{\circ}$ 57, Ano XIX, São Paulo, Cortez Editora, julho 1998, pp. 83-109.

SCAVONE, Lucila. Dar e cuidar da vida: feminismo e ciências sociais. São Paulo, UNESP, 2004.

- A maternidade e o feminismo: diálogo com as Ciências Sociais. Cadernos Pagu (16), Campinas-SP, Núcleo de Estudos de Gênero - Pagu/Unicamp, 2001, pp.137-150.

SCHWENGBER, Maria Simone Vione. Donas de Si? A educação de corpos grávidos no contexto da Pais \& Filhos. Tese Doutorado em Educação, Universidade Federal do Rio Grande do Sul-UFRGS, 2006.

SFEZ, Lucien. A saúde perfeita: crítica de uma nova utopia. São Paulo, Unimarco/Loyola, 1995.

SiBILIA, Paula. O pavor da carne: risco da pureza e do sacrifício no corpo-imagem contemporâneo. Revista Famecos, $\mathrm{n}^{\circ}$ 25, Porto Alegre, dez. 2004, pp. 68-84. 
Discursos que (con)formam corpos grávidos

SILVA, Tomaz Tadeu. A produção social da identidade e da diferença. In: SILVA, Tomaz Tadeu. (org. e trad.) Identidade e diferença: a perspectiva dos estudos culturais. Petrópolis, Vozes, 2000, pp.105131.

SOARES, Carmen. Práticas corporais: invenção de pedagogias? In: SILVA, Ana Márcia; DAMIANI, lara Regina (org.). Práticas corporais. Florianópolis, Naemblu Ciência e Arte, 2005, pp.17-46.

Arquitetura e educação do corpo: notas indicadas. SOARES, C. L, ZARANKIN. Revista do Núcleo de Desenvolvimento da Criatividade da UNICAMP, vol. 10, $\mathrm{n}^{\circ}$ 1, Campinas, NUDECRI-UNICAMP, 2004, pp.23-35.

Cultura de Movimento. Revista do SESC: Corpo Prazer e Movimento. São Paulo, 2003a.

Educação física: raízes européias e Brasil. $2^{\mathrm{a} e d}$. Campinas, Autores Associados, 1994.

VAZ, Paulo Roberto G. Corpo e Risco. Fórum Media, 2004. Disponível em: $<$ http://www.eco.ufrj.br/ paulovaz/textos/corpoerisc.pdf > Acesso: em 06/mar/2006.

VIRILIO, Paul. Os motores da história. In: ARAUJO, Hermes Reis (org.). Tecnociência e cultura: ensaios sobre o tempo presente. São Paulo, Estação Liberdade, 1996, pp.29-36.

\section{Revistas consultadas}

PAIS \& FILHOS. São Paulo, Bloch e Manchete, 1977-2007. 